\title{
Erratum to: Stress in NHS staff triggers defensive inward-focussing and an associated loss of connection with colleagues: this is reversed by Schwartz Rounds
}

\author{
Melanie S. George
}

\section{Erratum}

Unfortunately, after publication of this article [1], it was noticed that in the section 'Background' under the subsection 'The expansion within the NHS', the amount of funding mentioned that was provided by the government was $£ 650$ million. This funding amount should instead have been $£ 650,000$. The original article has been updated to correct this error.

Received: 21 October 2016 Accepted: 24 October 2016

Published online: 08 November 2016

\section{Reference}

1. George MS. Stress in NHS staff triggers defensive inward-focussing and an associated loss of connection with colleagues: this is reversed by Schwartz Rounds. Journal of Compassionate Health Care. 2016;3:9. doi:10.1186/ s40639-016-0025-8. 